\title{
Dynamic strength analysis of the key components of the beam-type pumping unit with dynamic tracking balance
}

\author{
Bo Wang, De-Chun Chen \\ School of Petroleum Engineering, China University of Petroleum (East China), Qingdao, 266580, China. \\ s20060010@s.upc.edu.cn
}

ABSTRACT. Aiming at the shortages of large reversing impact, high energy consumption and poor balance effect of conventional beam-type pumping unit, the design scheme of beam-type pumping unit with dynamic tracking balance is proposed. The load-displacement curves from on-site trial shows that the pumping with dynamic tracking balance has a better effect of load balance, and a high production and power efficiency. According to the designed structure, the dynamic responses of the beam and connecting rods are analyzed. The results show that the maximum Von Mises stresses in the beam and connecting rods are $36.96 \mathrm{MPa}$ and $27.83 \mathrm{MPa}$, respectively. The key components of designed beam-type pumping unit with dynamic tracking balance meet the requirement of strength.

KEYwORDS. Dynamic tracking balance; Load balance; Power efficiency; Dynamic response; Strength.

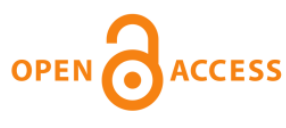

Citation: Wang, B., Chen, D. C., Dynamic strength analysis of the key components of the beam-type pumping unit with dynamic tracking balance, Frattura ed Integrità Strutturale, 57 (2021) 291-299.

Received: 24.04.2021

Accepted: 10.06 .2021

Published: 01.07.2021

Copyright: (C) 2021 This is an open access article under the terms of the CC-BY 4.0, which permits unrestricted use, distribution, and reproduction in any medium, provided the original author and source are credited.

\section{INTRODUCTION}

$\mathrm{O}$ il extraction with sucker rod is the most important way of oil production in China and even all over the world. According to the statistics, more than $80 \%$ of the total crude oil in China is extracted by sucker rod pumping system, which accounts for nearly $90 \%$ output of the total oil wells in service [1]. The sucker rod pumping system is mainly composed of ground oil pumping unit, downhole pump and sucker rod, among which the oil pumping unit is the core lifting element. According to the structural characteristics, pumping units can be divided into beam pumping and non-beam pumping types. The main feature of the beam-type pumping unit is to change the reciprocating swing of beam into the reciprocating linear motion of suspension point by the arc surface of horse-head. The conventional beam-type pumping unit has the advantages of simple structure, convenient operation, high reliability and good adaptability to various working conditions. Therefore, it is always the dominated rod pumping unit in onshore oilfields, and will still be the preferred pumping unit for a long time in the future. However, the conventional beam-type pumping unit also has the deficiencies such as poor balance effect, large fluctuation of net torque of crank shaft, low efficiency and high energy consumption [2]. The statistics show that the average system efficiency of pumping wells in the oilfields of China is less than $25 \%$, the annual power consumption of oil production is about 9 billion $\mathrm{kWh}$, accounting for about 
$45 \%$ of the total energy consumption of oilfields. Therefore, reducing energy consumption has become one of the important topics in front of the oilfield development $[3,4]$.

At present, three approaches are commonly adopted on energy savings in oil-gas extraction. First one is the improvement of pumping unit structure. For example, double-horsehead pumping unit [5, 6], pumping unit balanced with phased crank [7], and pump-stroke optimization [8] have been adopted to improve the structure of pumping unit. The second one is employing the specially designed motor, such as high-slip motor, super-high-slip motor, and permanent-magnet motor, to improve the motor efficiency $[9,10]$. The third approach is to control the motor speed properly according to the operating condition of the oil well through power electronic devices, such as multifunction energy-saving device, frequency converter, and energy feedback device [11-16]. Although the former two approaches have positive effect on the overall efficiency, it is not economically justifiable to replace the old pumping units with new ones while they are still functioning. Since it only inserts another device in a pumping system without altering the overall structure, the third approach is a favorable solution from the practical application.

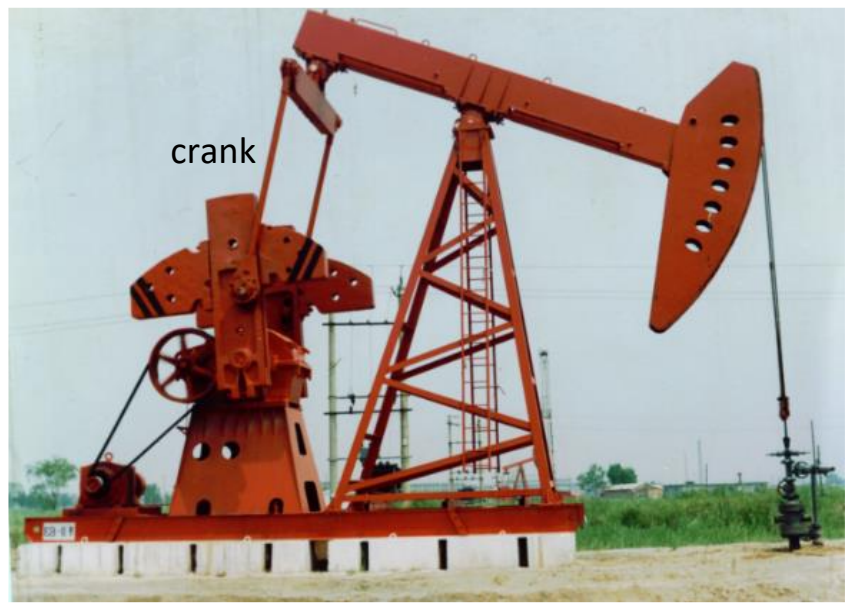

Figure 1: The conventional beam pumping unit

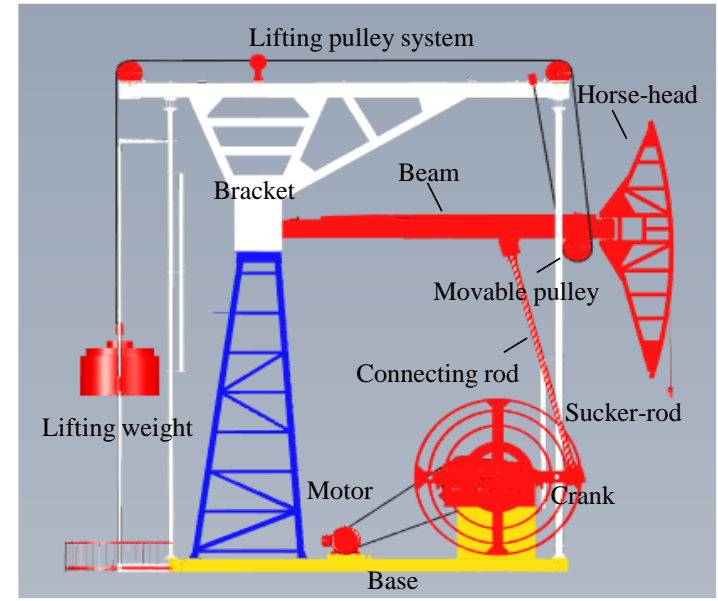

Figure 2: Beam-type pumping unit with dynamic tracking balance

The beam-type pumping unit with dynamic tracking balance is a typical front-mounted pumping unit, with the structure shown in Figure 2. When compared with the conventional beam pumping unit, the swing angle of the front-mounted beam is small, which effectively reduces the change rate of load and ensures the stability during the up-down strokes. In order to improve the motion characteristics of the pumping unit, the dynamic tracking balance is designed to improve the effect of load balance by assembling a moving pulley, which can automatically adjust the arm of force on the beam from the balance of moment according to the loads from suspension point and connecting rod at different positions. Compared with the moment balance of the beam by the rear-mounted crank in the traditional pumping unit, as shown in Figure 1, the moment balance of the beam with dynamic tracking balance can be accomplished by a lifting weight, which can eliminate the negative torque reduce the peak torque from the rear-mounted crank simultaneously. The movable pulley can generate the force twice the lifting weight, and the moment from the lifting weight can adjust directly from the movement of pulley, to balance the moment from the suspended load automatically. Meanwhile, the lifting weight can be also changed to achieve the close even equal peak powers in the up and down strokes, and to reduce the power fluctuation of motor. So the dynamic tracking balance can effectively reduce the matching power capacity of the pump and improve the mechanical efficiency in terms of energy saving effect [17]. Now the preliminary industrial application of the beamtype pumping unit with dynamic tracking balance has been promoted in Yanchang oilfield in western China, and the result shows that the energy saving effect of dynamic tracking balance is remarkable. However, the fact is that the developed small-scale pumping unit cannot meet the increasing requirements of large liquid extraction and deep well pumping. Therefore, a large-scale beam-type pumping unit with dynamic tracking balance as well as its supporting intelligent control system have been put on the agenda since 2016.

As a new type of pumping unit, its technical features and dynamic strength of the key components are worthy of attentions. So far, the kinematic and stress analysis of the key components of beam-type pumping unit are available [18-20]. However, these work are mainly focus on the high-slip motors and double horse-head pumping units [21-23]. No previous research 
work has been done to study the dynamic behavior of beam-type pumping unit with dynamic tracking balance. To make up this deficiency and provide the guidance of the structural design, in this paper, the working principle and efficiency of beam-type pumping unit with dynamic tracking balance are investigated, and the dynamic strength analysis of the key components are analyzed by the finite element method.

\section{TECHNICAL FEATURES OF DYNAMIC TRACKING BALANCE}

\section{Working principle}

7 he beam-type pumping unit with dynamic tracking balance is composed of base, bracket, front-mounted beam, horse-head, lifting pulley system, crank, connecting rod, motor and other parts, as shown in Figure 2 . The frontmounted beam is hinged on the bracket, and is driven to swing up and down by the crank-connecting rod system. The steel wire rope connected with the balance weight is fixed on the bracket, which can apply the force to the beam through a group of pulleys, to balance with the moment to the bracket caused by the suspension load from the sucker rod. The crank-connecting rod mechanism changes the rotation of crank wheel driven by motor into the up and down swing of the traveling beam through the reciprocating push-pull motion of the connecting rod. When the beam swings up, the lifting moment from the gravity of the lifting weight is applied to the beam assisting the oil pumping, when the beam swings down, the lifting block is raised to accumulate the potential energy.

The main technical features of the developed beam pumping unit with dynamic tracking balance are listed as follows:

(1) The support and the bracket can bear all the pumping load and counterweight load, and the operation safety is excellent.

(2) The designed pulley block mechanism can generate the balance moment with less lifting blocks and it is convenient to increase or decrease the balance weight.

(3) The swing angle of the front traveling beam is small, so the mechanism can run smoothly.

(4) The hanging rope is in good neutral position, and the service life of the pump rod ban be extended.

(5) The forces of the driving parts is smaller than those in the conventional beam pumping unit.

(6) The motor power can be reduced and the situation of negative torque can be prevented, which greatly improves the service life of the motor.

Benefited from the above design, the beam-type pumping unit with dynamic tracking balance can better adapt to different well conditions. At the same time, the motion characteristics are completely controllable, and the pumping unit exhibits the performance of high efficiency and energy saving, safe and convenient management.

\begin{tabular}{ccccc}
\hline Type of bumping & Balance $(\%)$ & $\begin{array}{c}\text { Effective power } \\
(\%)\end{array}$ & System efficiency $(\%)$ & $\begin{array}{c}\text { Electricity consumption } \\
\text { per ton liquid lifting } \\
100 \text { meter } \\
(\mathrm{kWh} / 100 \mathrm{~m} \cdot \mathrm{t})\end{array}$ \\
$\begin{array}{c}\text { Beam-type } \\
\text { pumping with }\end{array}$ & 113.12 & 1.09 & 13.54 & 2.01 \\
$\begin{array}{c}\text { dynamic tracking } \\
\text { balance }\end{array}$ & 102.01 & 1.09 & 11.71 & 2.32 \\
\hline & 107.57 & 1.09 & 12.63 & 2.17 \\
$\begin{array}{c}\text { Traditional } \\
\text { beam-type }\end{array}$ & 134.54 & 1.09 & 12.55 & 2.17 \\
pumping & 69.17 & 0.78 & 9.52 & 2.86 \\
& 73.13 & 0.78 & 9.28 & 2.93 \\
\hline
\end{tabular}

Table 1: Comparison of balance and power efficiency between the traditional beam-type pumping and beam-type pumping with dynamic tracking balance. 


\section{Balance effect and production efficiency}

At present, the conventional large-scale beam-type pumping unit has been replaced by the dynamic tracking balanced one in Shuai 5-17 oil well in the Huadong oilfield of China. The differences of load balance and operational efficiency between the conventional beam pumping unit and dynamic tracking balanced one are listed in Table 1. It can be seen that the overall performance of beam-type pumping unit with dynamic tracking balance outweighs that of the conventional one, which attributes to the fact that the dynamic tracking balance can effectively improve the effect of load balance and reduce the power loss.
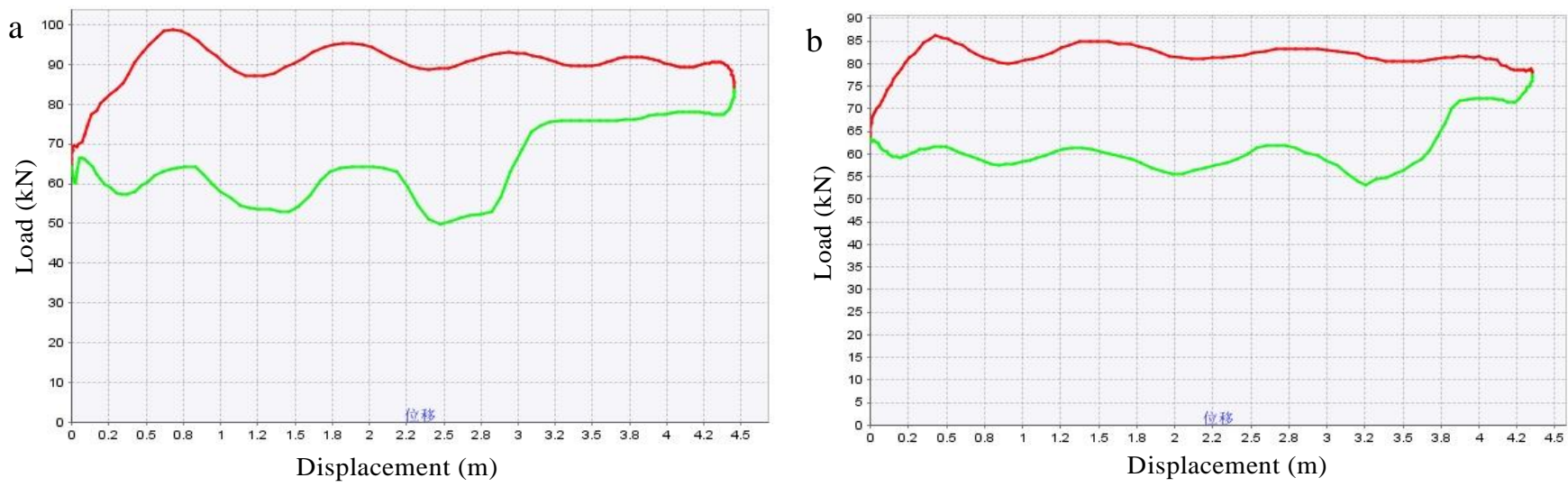

Figure 3: The comparison of load-displacement curves (a. traditional beam-type pumping; b. beam-type pumping with dynamic tracking balance).

The load-displacement curves of the traditional beam-type pumping unit and dynamic tracking balanced one are compared in Figure 3. The load-displacement curve of the beam-type pumping unit with dynamic tracking balance is more regular than that of the conventional one. The included area of the load-displacement curve of the pumping unit with dynamic tracking balance is smaller, which means that less power is needed during the oil extraction. The curve fluctuation of the dynamic tracking balance is also small, this fact indicates the vibration of suspension load is small and the whole pumping unit runs more smoothly. In addition, the down-stroke (in green) in load-displacement curve mainly reflects the load fluctuation and the storage of potential energy during the lifting of balance weight. The curve of dynamic tracking balanced one in the down-stroke is much stable than that of the conventional unit and the efficiency of load balance is better.

\section{DYNAMIC ANALYSIS OF THE KEY COMPONENTS}

\section{Analysis of suspension load}

7 he mechanism diagram of the beam-type pumping with dynamic tracking balance is shown in Figure 4. The crank, the horse-head and beam are subjected to the torque $M$ from the motor, the suspension load $P_{1}$ and the balance weight $P_{2}$. In the up-stroke and down-stroke processed, the suspension loads can be expressed as [2, 24]

$$
\left\{\begin{array}{l}
P_{1 \mathrm{u}}=W_{j u}+W_{i u}+W_{v u}+F_{u} \\
P_{1 \mathrm{~d}}=W_{j d}-W_{i d}-W_{v u}-F_{d}
\end{array}\right.
$$

where $W_{j u}, W_{i u}, W_{v u}$ and $F_{u}$ are the static load, inertial load, vibration load and friction load in the up-stroke, respectively, and $W_{j d}, W_{i d}, W_{v d}$ and $F_{d}$ are the static load, inertial load, vibration load and friction load in the down-stroke, respectively. When the bottom of the oil tubing is anchored, the vibration load could be ignored, then equation (1) can be rewritten as

$$
\left\{\begin{array}{l}
P_{1 \mathrm{u}}=\left(A_{r} \rho_{r} g L_{p}+\rho_{L} g L_{p}\left(A_{p}-A_{r}\right)-\rho_{L} g h_{M} A_{p}\right)+\left(W_{r} \frac{a_{r}}{\mathrm{~g}}+\varepsilon W_{L} \frac{a_{r}}{\mathrm{~g}}\right)+F_{u} \\
P_{1 \mathrm{~d}}=\left(A_{r} \rho_{r} g L_{p}+\rho_{L} g L_{p}\left(A_{p}-A_{r}\right)-\rho_{L} g h_{M} A_{p}\right)-W_{r} \frac{a_{r}}{\mathrm{~g}}-F_{d}
\end{array}\right.
$$


where $\varrho_{r}$ and $A_{r}$ are the density and cross-section area of sucker rod, $\mathrm{g}$ is the acceleration of gravity, $L_{\mathrm{p}}$ is the length of sucker rod string, $\varrho_{L}$ is the density of liquid in the well, $A_{\mathrm{p}}$ the cross-section area of plunger, $b_{\mathrm{M}}$ is the submergence depth, $W_{r}$ and $\mathrm{W}_{L}$ are the weights of sucker rod and liquid column, $\varepsilon$ is the correction coefficient of acceleration, and $a_{r}$ is the acceleration of sucker rod.

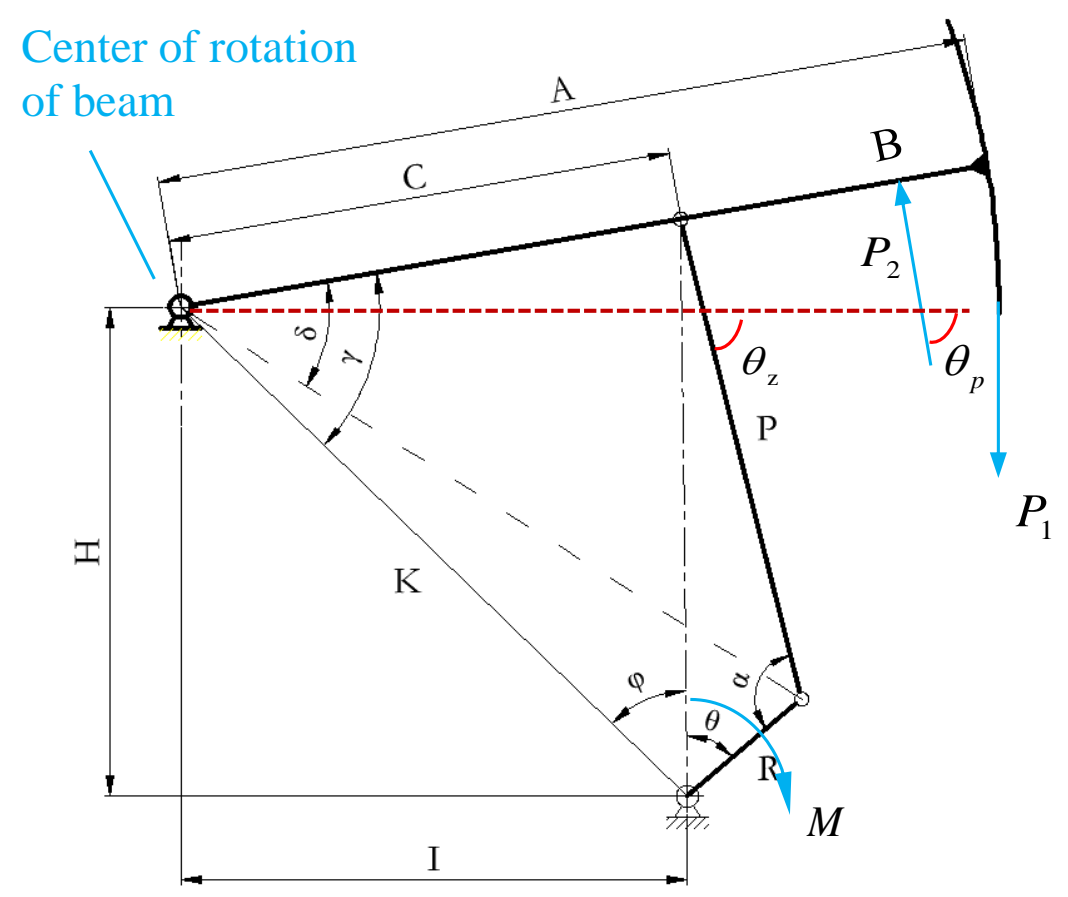

Figure 4: Mechanism diagram of beam-type pumping with dynamic tracking balance.

The balance weight $P_{2}$ can be determined by the balance of the beam. The moment balance of the rotating center of the beam yields:

$$
P_{2}=\frac{P_{1} L_{\mathrm{A}}+G_{1} L_{1}+G_{y} L_{y}-F_{z} \cos \theta_{z} L_{\mathrm{C}}}{2 \cos \theta_{p} L_{\mathrm{B}}}
$$

where $G_{1}$ is the weight of the horse-head, $G_{y}$ is the weight of the beam, $F z$ is the reaction force from connecting rod, $\theta_{z}$ is the angle between connecting rod force and horizontal line, $\theta p$ is the angle between steel wire rope of upper moving pulley on the beam and horizontal line, and $L_{\mathrm{A}}$ is the distance from suspension point to rotation center of the beam, $L_{\mathrm{B}}$ is the distance from moving pulley center to rotation center of the beam, $L_{C}$ is the distance between the bearing center of connecting rod and beam to the rotation center of the beam. In this work, the external loads except the gravity to the pumping unit are listed in Table 2, and the stroke distance is $4.5 \mathrm{~m}$.

\begin{tabular}{|c|c|c|c|}
\hline $\begin{array}{l}\text { Parameter } \\
\text { Stroke period }\end{array}$ & Suspension load $P_{1}(\mathrm{kN})$ & $\begin{array}{l}\text { Torque } M \text { at the crank } \\
\qquad(\mathrm{kN} . \mathrm{m})\end{array}$ & Weight of balance $P_{2}(\mathrm{kN})$ \\
\hline $4 \mathrm{~min}$ & 140 & 37.26 & 80 \\
\hline $5 \mathrm{~min}$ & 140 & 43.72 & 78 \\
\hline $6 \mathrm{~min}$ & 140 & 49.88 & 77 \\
\hline
\end{tabular}

Table 2: Loads of beam-type pumping with dynamic tracking balance at different stroke periods. 


\section{DYNAMIC SIMULATION FOR KEY COMPONENTS OF BEAM-TYPE PUMPING WITH DYNAMIC TRSCKING BALANCE}

\section{Finite element model}

he finite element of crank-connecting rod-beam is shown in Figure 5. The degrees of freedom of the left end of the beam and the center of crank wheel are constrained by the pin. The crank wheel is applied the angular velocity, and the beam is applied the suspension load at the horse-head. According to the moving track and the center line of the lifting pulley system, a user subroutine is programmed in the ABAQUS to accomplish the location variations of loading $P_{2}$ according to the dynamic tracking balance.

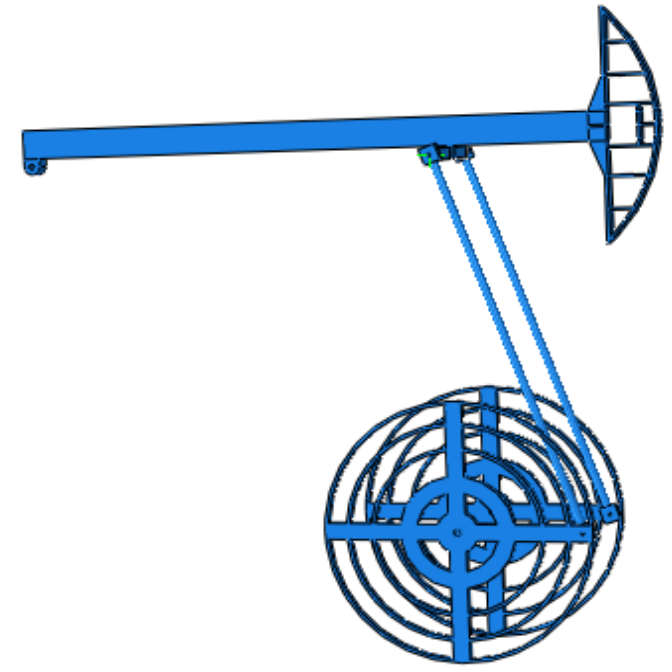

(a) Geometric model

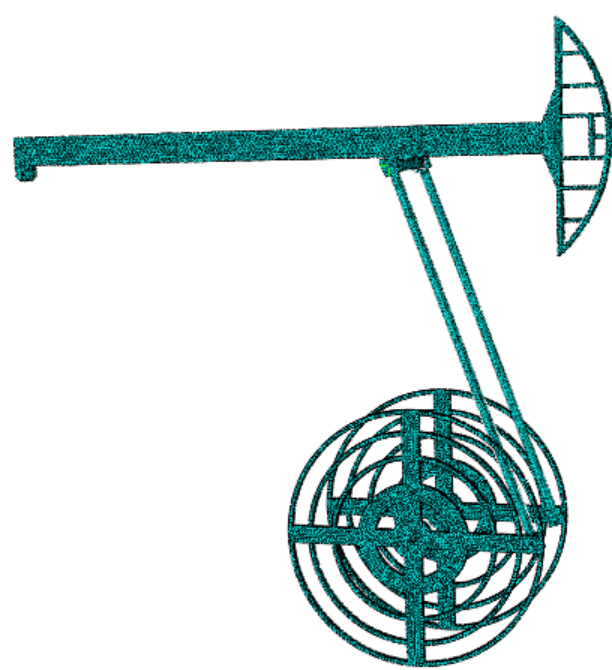

(b) Finite element model

Figure 5: The finite element model of the beam-type pumping with dynamic tracking balance.

\section{Dynamic response of the key components}

Figure 6 demonstrates the variations of displacement, velocity and acceleration of the suspension point. The displacement curve of the suspension point is close to a cosine curve, and its stroke length is close to the design value $4.5 \mathrm{~m}$. According to the speed curve of the suspension point, the speed change of the pumping unit is relatively stable, and there is no speed mutation. When the suspension point is close to the top of the up-stroke and down-stroke, the speed reaches the maximum, and the beam is in the horizontal position, which is very consistent with the motion of a four-bar structure. Through the acceleration curve of the suspension point, it can be seen that when the horse head of the pumping unit reaches the upper and lower dead points, the displacement of the suspension point is the largest. At this time, the speed almost approaches to zero, and the acceleration reaches its maximum at the same time.

Figure 7 shows the Von Mises stress distribution of the beam and connecting rod under the static maximum load. A cross brace is welded at the bottom of the beam to support the connecting rods. The maximum stress of the beam occurs at the junction of the beam and the cross brace, and the maximum stress is $25.05 \mathrm{MPa}$, as shown point $\mathrm{A}$ in Figure 7(a). The cross brace and connecting rod are connected by pin, and the maximum stress on both sides appears at the bottom of the joint, and the maximum stress is $21.87 \mathrm{MPa}$, as shown in Figure 7(b).

Figure 8 shows the dynamic Von Mises stress variations of points A and B in the oil extraction process. It can be seen that the dynamic stress variations exhibit a good periodicity, which is consistent with the actual stroke cycle. The maximum Von Mises stresses of points $\mathrm{A}$ and $\mathrm{B}$ are $36.96 \mathrm{MPa}$ and $27.83 \mathrm{MPa}$. It can be concluded that dynamic load factors of the beam and connecting rod are 1.48 and 1.27, respectively. The pumping unit is made of 45 carbon steel with yield stress $425 \mathrm{MPa}$. Therefore, the key components of the designed beam-type pumping with dynamic tracking balance can meet the requirement of strength. 


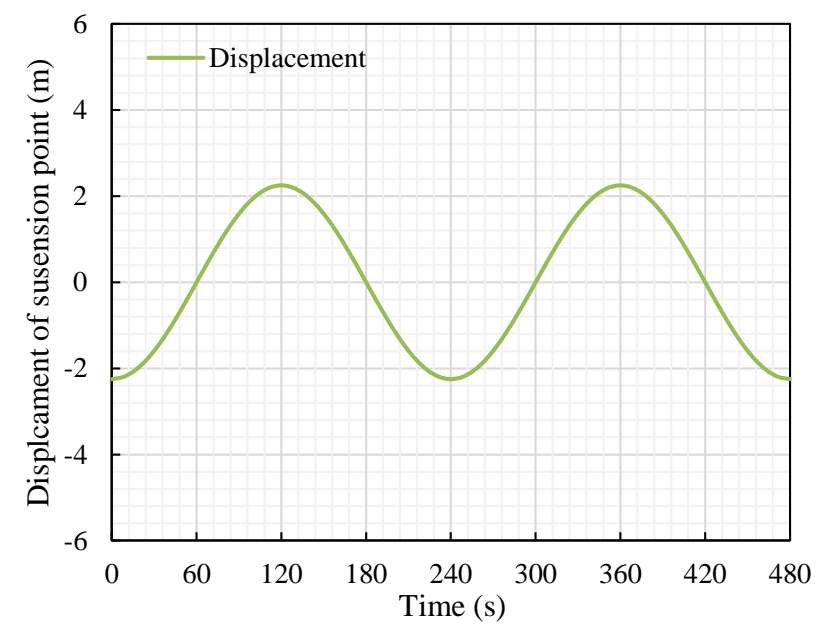

(a) Displacement

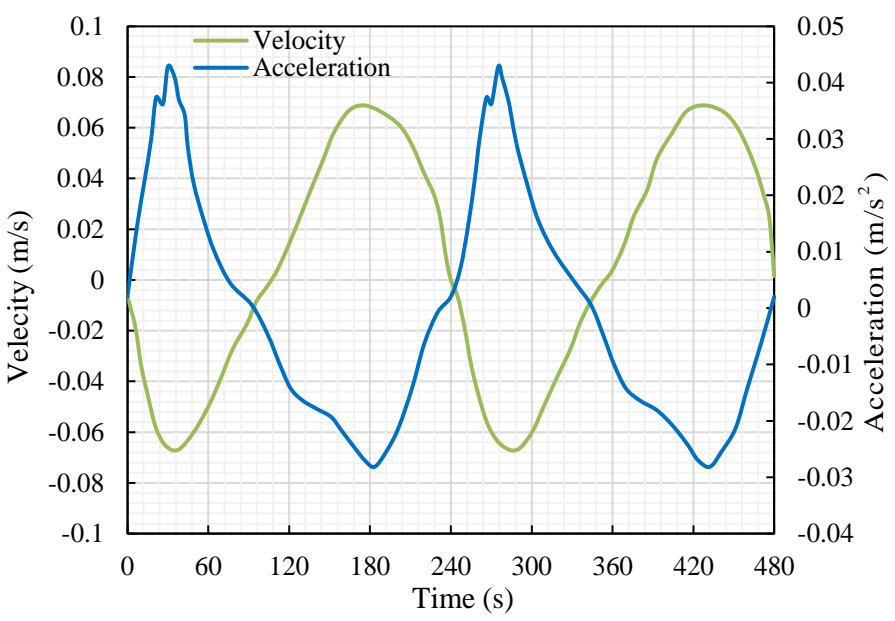

(b) Velocity and acceleration

Figure 6: Motion response of the suspension point.

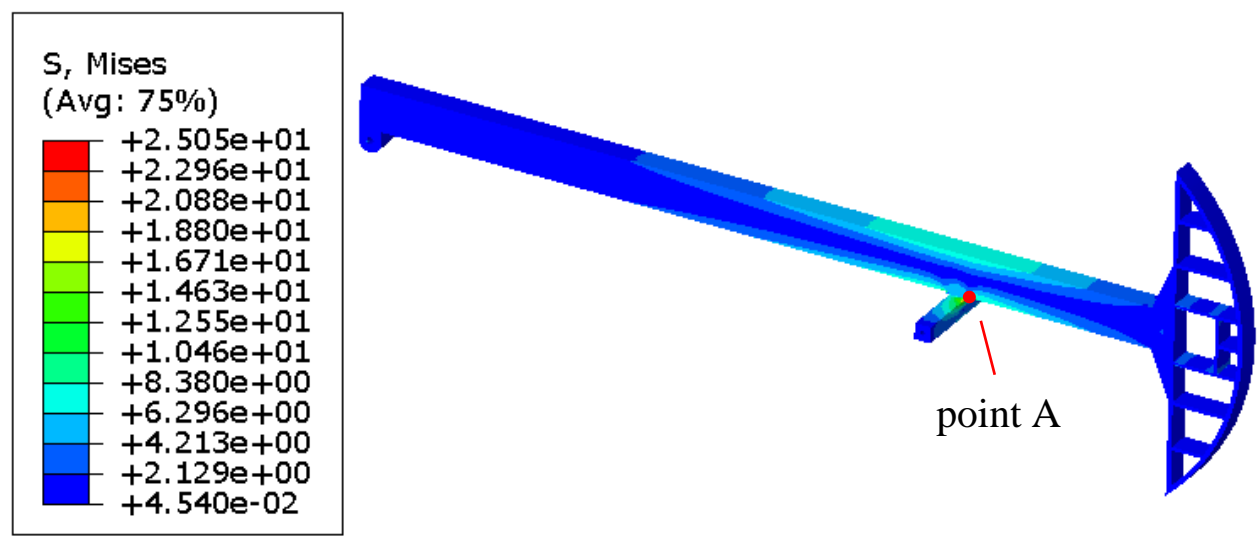

(a) Beam
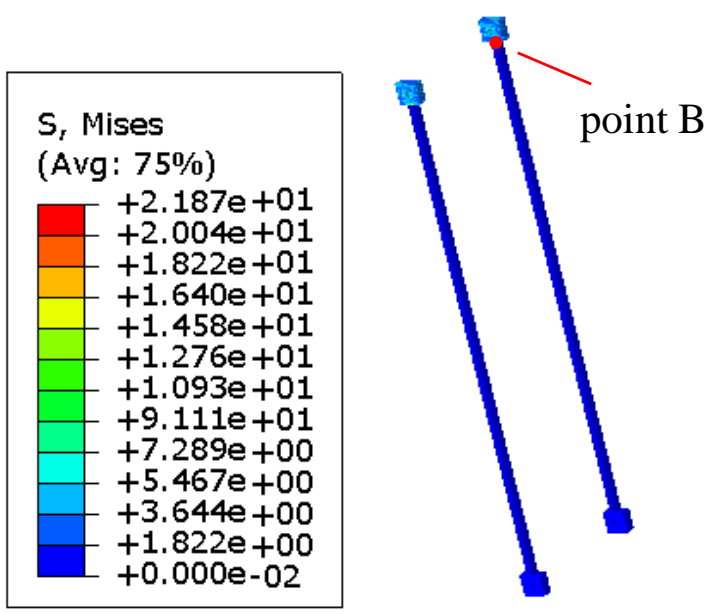

(b) Connecting rod

Figure 7: The Von Mises stress of the beam and the connecting rods under the static maximum load 


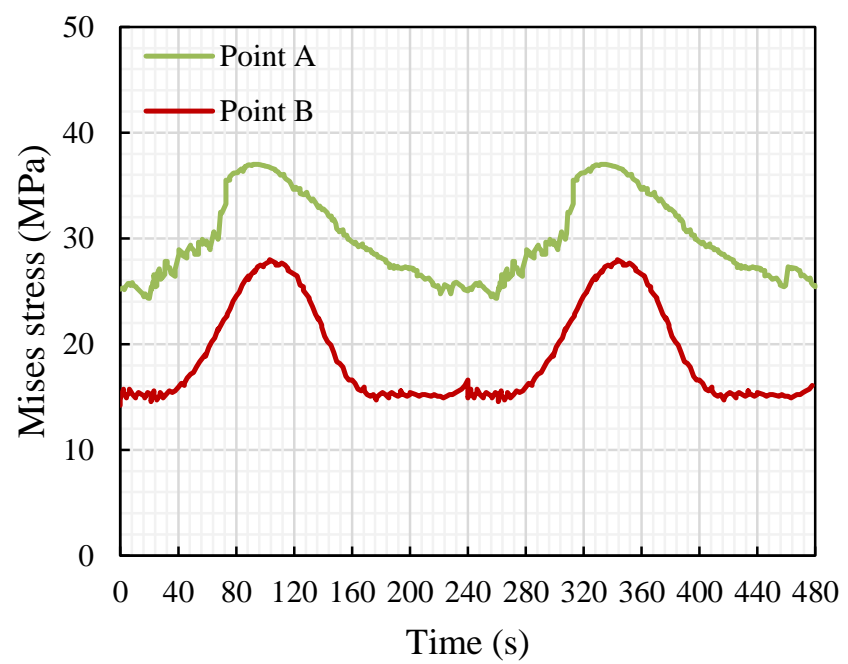

Figure 8: The Von Mises stress variation with time at points A and B (stroke period: 4 min).

\section{CONCLUSION}

I $\mathrm{n}$ the present study, the technical feature of beam-type pumping unit with dynamic tracking balance is analyzed. When compared with the conventional beam-type pumping unit, the pumping unit with dynamic tracking balance has a better balance effect and production efficiency. Benefit from the dynamic tracking balance design, it has a more regular load-displacement curve and effectively reduce the load fluctuation in the operation process.

According to the dynamic analysis, the dynamic stress variations of the key components of the beam-type pumping unit with dynamic tracking balance are obtained. The results show that the maximum in the beam and connecting rod are 36.96 $\mathrm{MPa}$ and $27.83 \mathrm{MPa}$, and the structural design of the pumping unit with dynamic tracking balance is reasonable and efficient.

\section{ACKNOWLEDGMENTS}

he research work is supported by the Natural Science Foundation of Shandong Province (No. ZR2020ME092), the National Natural Science Foundation of China (No.51404286), and the Fundamental Research Funds for the Central Universities of China (No.20CX02308A).

\section{REFERENCES}

[1] Feng, Z.M., Guo, C.H., Zhang, D.S., Cui, W., Tan, C.D., Xu, X.F., Zhang, Y. (2020). Variable speed drive optimization model and analysis of comprehensive performance of beam pumping unit. Journal of Petroleum Science and Engineering, 191, pp.107155. DOI: 10.1016/j.petrol.2020.107155.

[2] Lu, J. M, He, J.P, Mao, C.X, Wu, W.W., Wang, D., Lee, W.J. (2014). Design and implementation of a dual PWM frequency converter used in beam pumping unit for energy saving. IEEE Transactions on Industry Applications, 50(5), pp.2948-2956. DOI: 10.1109/TIA.2014.2304621.

[3] Langbauer C. (2018). Sucker rod pumping system optimisation based on a novel finite elements analysis. SPE-192475MS, SPE Middle East Artificial Lift Conference and Exhibition, pp.1-13. DOI: 10.2118/192475-MS.

[4] Kochtik, D., Langbauer, C. (2018). Volumetric efficiency evaluation of sucker-rod-pumping applications performed on a pump testing facility. SPE-192454-MS. SPE Middle East Artificial Lift Conference and Exhibition, pp.1-11. DOI: 10.2118/192454-MS. 
[5] Long, Q. Z., Gui, J. C., Zhang, X., Fu, H.L. (2016). Study on mechanical performance simulation method of key components in double horse head pumping unit. IEEE International Conference on Ubiquitous Robots \& Ambient Intelligence, pp.152-156. DOI: 10.1109/URAI.2016.7734044.

[6] Wu, W., Xu, T., He, P.F. (2019). Development of analysis and optimization software for dual horse head pumping unit with single arc back horse head based on GUI editor. IOP Conference Series: Earth and Environmental Science 242, pp.022052. DOI: $10.1088 / 1755-1315 / 242 / 2 / 022052$.

[7] Feng, Z.M, Zhang, J.D., Gu, H.B., Luan, Y.W. (2013). Research on energy-saving technology of crank balanced pumping unit. Research Journal of Applied Sciences Engineering and Technology, 6(22), pp.4152-4157. DOI: $10.19026 /$ rjaset. 6.3525 .

[8] Elmer, W.G., Elmer, J.B. (2018). Pump-stroke optimization: case study of twenty-well pilot. SPE Production \& Operations, 33, pp.419-436. DOI: 10.2118/181228-MS.

[9] Leng, X.M., Liu, H. T. (2007). Design on the high-efficiency PM synchronous motor with high start torque in purpose of drawing out oil. Electrical Machinery Technology, 3, pp. 5-7. (in Chinese)

[10] Feng, Z., Ma, Q.Y., Liu, X.L., Cui, W., Tan, C.D., Liu, Y. (2020). Dynamic coupling modelling and application case analysis of high-slip motors and pumping units. PLoS One, 15(1), pp. e0227827. DOI: 10.1371/journal.pone.0227827.

[11] Luo, Y. L., Cui, X. S., Zhao, H. S. (2011). A multifunction energy-saving device with a novel power-off control strategy for beam pumping motors. IEEE Industry Applications Society 56th Annual Petroleum and Chemical Industry Conference, Anaheim, CA, USA, pp. 1606-1611. DOI: 10.1109/PCICON.2009.5297164.

[12] Gogolyuk, P., Lysiak, V., Grinberg, I. (2008). Influence of a frequency control strategies on induction motor-centrifugal pump unit and its modes. IEEE International Symposium on Industrial Electronics, pp. 656-661.

DOI: $10.1109 /$ ISIE. 2008.4676893.

[13] He, J.P., Ji, K., Xu, M., Mei, G.Z., Lin, D.R., Xia, H.J. (2018). Analysis of variable frequency energy-saving operation of beam pumping unit. IOP Conference Series: Materials Science and Engineering, 452, 4, pp.042185. DOI: $10.1088 / 1757-899 \mathrm{X} / 452 / 4 / 042185$.

[14] Lv, H.Q., Liu, J., Han, J.Q., An, J. (2016). An energy saving system for a beam pumping unit. Sensors, 16(5), pp.685. DOI: $10.3390 / \mathrm{s} 16050685$.

[15] Abdullah, A., Luis, V.R., Antonio, A.M., Angus, M., Haytham, R., Khalid, S., Dimas, L.P., Amur, H., Khadija, S., Shehu, A. Kevin, D.A. (2017). Self optimizing thermal field using beam pumps with variable speed drive. SPE-188137-MS. SPE Kingdom of Saudi Arabia Annual Technical Symposium and Exhibition, pp. 1-11. DOI: 10.2118/188137-MS.

[16] Napoles, J., Leon, J.I., Portillo, R., Franquelo, L.G., Aguirre, M.A. (2010). Selective harmonic mitigation technique for high-power converters. IEEE Transactions on Industrial Electronics, 57(7), pp.2315-2323.

DOI: 10.1109 /TIE.2009. 2026759.

[17] Liu, L.H. (2019). Calculation and study of balance performance of oil pumping unit with dynamic balance. Machinery, 11(45), pp.27-30. (in Chinese)

[18] Chang, Z.Y., Yu, Y.Q., Qi, Y.G. (2017). Study on dynamic characteristics of hydraulic pumping unit on offshore platform. China Ocean Engineering, 31(006), pp.693-699. DOI:10.1007/s13344-017-0079-1.

[19] Larrainzar, C., Korin, I., Ipiña, J. P. (2010). Analysis of fatigue crack growth and estimation of residual life of the walking beam of an oilfield pumping unit. Engineering Failure Analysis, 17(5), pp.1038-1050. DOI:10.1016/j.engfailanal. 2009.12.003.

[20] Carpenter, C. (2015). Reliability improvement in beam pumps by use of a unique methodology. Journal of Petroleum Technology, 67, pp.96-98. DOI: 10.2118/0715-0096-JPT.

[21] Bhagavatula, R., Fashesan, O. A., Heinze, L. R., Lea, J.F. A computational method for planar kinematic analysis of beam pumping units. Journal of Energy Resources Technology, 2007, 129(4), pp.300. DOI: 10.1115/1.2790981.

[22] Ding, H., Xie, J.F., Bai, Z.Q., Li, Y., Li, H.B. (2019). Fracture analysis of a connecting rod for oil pumping unit in china western oilfield. Engineering Failure Analysis, 105, pp.313-320. DOI:10.1016/j.engfailanal.2019.07.021.

[23] Hansen, B., Tolbert, B., Vernon, C., Hedengren, J.D. (2019). Model predictive automatic control of sucker rod pump system with simulation case study. Computers \& Chemical Engineering, 121, pp.265-284.

DOI: 10.1016/j.compchemeng. 2018.08.018.

[24] Gibbs, S.G. (1975). Computing gearbox torque and motor loading for beam pumping units with consideration of inertia effects. Journal of Petroleum Technology, 27 (9), pp.1153-1159. DOI: 10.2118/5149-PA. 